\title{
Computer simulation of the coffee leaf miner using sexual Penna aging model
}

\author{
A.C.S. de Oliveira ${ }^{a}$, S.G.F. Martins ${ }^{a, *}$, M.S. Zacarias ${ }^{b}$ \\ a Departamento de Ciências Exatas, Universidade Federal de Lavras, Caixa Postal 3037, CEP: 37200-000, Lavras-MG, Brazil \\ ${ }^{\mathrm{b}}$ Embrapa Café/EcoCentro, Campus UFLA, Caixa Postal 176, CEP: 37200-000, Lavras-MG, Brazil
}

Received 31 July 2007; received in revised form 10 September 2007

Available online 16 October 2007

\begin{abstract}
Forecast models based on climatic conditions are of great interest in Integrated Pest Management (IPM) programs. The success of these models depends, among other factors, on the knowledge of the temperature effect on the pests' population dynamics. In this direction, a computer simulation was made for the population dynamics of the coffee leaf miner, L. coffeella, at different temperatures, considering experimental data relative to the pest. The age structure was inserted into the dynamics through sexual Penna Model. The results obtained, such as life expectancy, growth rate and annual generations' number, in agreement to those in laboratory and field conditions, show that the simulation can be used as a forecast model for controlling L. coffeella.
\end{abstract}

(c) 2007 Elsevier B.V. All rights reserved.

Keywords: Population dynamics; Forecast model; Aging

\section{Introduction}

The Integrated Pest Management (IPM) is a pest controlling system in which all possible control options (biological, chemical, cultural, manual and mechanical) are evaluated and one or more are selected for prevention or remediation of unacceptable pest activity or damage. The control option(s) choice is based on the efficiency, environmental impact, site characteristics, health risk and economy [1]. Forecast models based on climatic conditions are of great interest for planning control actions. Methods of degree-days [2,3] are useful tools for forecasting pest population peaks, through estimation of the generation number.

The insect "coffee leaf miner", Leucoptera coffeella (Guérin Mèneville, 1842), is one of the most important pests of the coffee due to the economic damages caused by this insect in the production of coffee. It is a pest from the African continent which only attacks coffee. Its presence has been evidenced in Brazil since 1851 [4].

The main method for controlling coffee leaf miner has been the use of chemical products. However, agents of biological control have played an important role, being sufficiently able to keep the population of the pest below the economic damage level in some regions [5].

\footnotetext{
* Corresponding author. Tel.: +55 353829 1383; fax: +55 3538291650 .

E-mail address: solangemarti@gmail.com (S.G.F. Martins).
} 
The knowledge of the effect of physical factors on the pests has great importance for designing integrated management strategies. Some researches in laboratory and field have been developed in an attempt to understand the effect of those factors on the population dynamics of the coffee leaf miner [2,4]. It was observed from these studies that temperature is a natural factor of great influence to life expectancy, development, egg-laying capacity and the average number of annual generations of L. coffeella.

Recently Giarolla et al. [6] had simulated the population dynamics of Aphis gossypii insects, one of the main pests on horticultural crops, using the asexual version of the Penna Model [7]. In the same way, given the importance to understand the population dynamics of $L$. coffeella, we proposed in this work, a model for pest population dynamics, using as reference the experimental data related to coffee leaf miner [2]. Considering the need of an age structure for the studies, we used the sexual version of the Penna Model [8,9]. This paper is organized as follows: in Section 2, we describe the sexual version of the Penna Model; in Section 3 we present some relative experimental comments on L. coffeella; in Sections 4 and 5, we describe the model and present our results and discussions; in Section 6 the conclusions are presented.

\section{Sexual version of the Penna Model}

The first sexual version of the Penna Model was introduced by Bernardes [8]. In this work we adopted a slightly different strategy introduced by Stauffer et al., [9] which will be described as follows. The population is divided into males and females. The individuals are diploids, with their genotypes represented by two bit-strings that are read in parallel. One of the bit-strings contains the genetic information inherited from the mother, and the other from the father. The individual stays alive if the number of deleterious mutations which became active up to its current age is lower than a threshold $T$. The position of the bits corresponds to the age at which this deleterious mutation starts to affect the health. In order to count the accumulated number of mutations and compare them with the threshold, it is necessary to distinguish between recessive and dominant mutations. A mutation is counted if two bits set to 1 appear at the same position in both bit-strings (inherited from both the parents) or if it appears in only one of the bit-strings but at a dominant position (locus). The dominant positions are randomly chosen at the beginning of the simulation and are the same for all individuals.

After reaching the minimum reproduction age $R$, a female randomly chooses a male with age equal to or greater than $R$ to breed. To construct one offspring genotype, first the two bit-strings of the mother are cut in a random position (crossing), producing four bit-string pieces. Two complementary pieces are chosen to form the female gamete (recombination). Finally, $m$ deleterious mutations are randomly introduced. The same process occurs with the male's genotype, producing the male gamete with $m$ deleterious mutations. These two resulting bit-strings form the offspring genotype. The sex of the baby is randomly chosen, with a probability of $50 \%$ for each one. This whole strategy is repeated $b$ times to produce the $b$ offspring.

As in the asexual version, the Verhulst killing factor is introduced. The individual will survive and will age by one year with probability $1-N(t) / N_{\max }$, where $N(t)$ is the population size at time $t$ and $N_{\max }$ is the capacity of the environment.

\section{Experimental comments about Leucoptera coffeella}

In laboratory conditions, Parra [2] evaluated at different temperatures the biological behavior of L. coffeella, whose life cycle is composed of the phases egg, larva, pupa and adult. For each temperature, the developmental time (duration of the phase of egg to adult), oviposition time, pre-oviposition time, duration of the egg phase, probability of oviposition, fecundity, growth rate, intrinsic growth rate (Table 1) and life expectancy for the adults (Table 2) were evaluated.

It was verified that the temperature of $27^{\circ} \mathrm{C}$ is the most favourable one for the population growth of L. coffeella, since the capacity of oviposition and the intrinsic growth rate had been higher at this temperature.

For the elaboration of forecast model for pest control it is very important to know the number of annual generations. In reference [2] a method was proposed, based on the addition of degree-days, ${ }^{1}$ to calculate the probable number of generations in a time interval where the temperature remains constant, which depends on the temperature and duration

${ }^{1}$ One degree-day is defined as the difference, in degree Celsius, between the daily average temperature and a base temperature. 
Table 1

Developmental time, oviposition time, pre-oviposition time, duration of the phase of egg (all in days), probability of oviposition, fecundity, growth rate and intrinsic growth rate of L. coffeella at the temperatures of 20,27 , and $30{ }^{\circ} \mathrm{C}$

\begin{tabular}{lccc}
\hline Temperature & $20{ }^{\circ} \mathrm{C}$ & $27^{\circ} \mathrm{C}$ & $30{ }^{\circ} \mathrm{C}$ \\
\hline Developmental time $(R)$ & 44 & 20 & 18 \\
Oviposition time $(\beta)$ & 11 & 19 & 2 \\
Pre-oviposition time $(\gamma)$ & 4 & 1 & 1 \\
Duration of the phase of egg $(\epsilon)$ & 10 & 5 & 4 \\
Probability of oviposition $(\alpha)$ & 0.33 & 0.93 & 0.66 \\
Fecundity $(B)$ & 9.6 & 60.9 & 9.7 \\
Growth rate $(\lambda)$ & 1.0 & 1.136 & 1.063 \\
Intrinsic growth rate $\left(r_{m}\right)$ & 0.0 & 0.13 & 0.06 \\
\hline
\end{tabular}

Table 2

Life expectancy of adults of $L$. coffeella (average \pm half length of the $95 \%$ confidence interval) in days at the temperatures of 20,27 , and $30{ }^{\circ} \mathrm{C}$

\begin{tabular}{llll}
\hline Temperature & $20^{\circ} \mathrm{C}$ & $27^{\circ} \mathrm{C}$ & $30{ }^{\circ} \mathrm{C}$ \\
\hline Life expectancy of males & $11.8 \pm 3.9$ & $11.0 \pm 4.1$ & $3.3 \pm 0.5$ \\
Life expectancy of females & $12.5 \pm 4.9$ & $13.7 \pm 3.6$ & $4.5 \pm 0.8$ \\
\hline
\end{tabular}

of the egg, larval and pupal phases. The duration and development threshold ${ }^{2}$ of each phase for different temperatures were obtained in laboratory conditions at constant temperature. From these data the thermal constants ${ }^{3}$ had been calculated in degree-days for different phases $(79.48,156.53$ and 67.81 degree-days for egg, larval and pupal phases, respectively), according to the equation:

$$
K_{i}=n_{i}\left(\theta_{L}-\theta_{b, i}\right),
$$

with $K_{i}$ the thermal constant of the $i$-th phase in degree-days, $n_{i}$ the duration of the $i$-th phase in days, $\theta_{L}$ the temperature in laboratory and $\theta_{b, i}$ the development threshold of the $i$-th phase, both in degree Celsius.

Having the thermal constants as reference, the duration of each phase at different constant temperatures, is calculated through the equation:

$$
n_{i}(\theta)=\frac{K_{i}}{\theta-\theta_{b, i}},
$$

with $\theta$ the temperature in degree Celsius. In field conditions, as the temperature is not constant, the average temperature is considered for calculation of the duration of each phase.

Finally, the probable generations' number $\left(G_{\bar{\theta}}\right)$ in time interval $(\delta t)$ is thus calculated through the following equation:

$$
G_{\bar{\theta}}=\frac{\delta t}{n_{1}+n_{2}+n_{3}}
$$

with $\delta t$ the time interval in days, $\bar{\theta}$ the calculated average temperature on $\delta t$ in degree Celsius, $n_{1}, n_{2}$ and $n_{3}$, the duration of the egg, larval and pupal phases at average temperature $\bar{\theta}$, in days, respectively.

The annual generations' number of $L$. coffeella $(\delta t=360$ days $)$ was calculated for some intervals of temperature defined through a mapping based on the annual average temperature of the state of São Paulo/Brazil. It was observed, a great variation in the number of generations and more than 12 generations per year in hotter regions (Table 5).

Based on a register of historic average of the temperature per "pentada" (to each 5 days), Parra [2] calculated the annual generations' number of L. coffeella in eight different coffee regions of the state of São Paulo/Brazil. Regions with average annual temperatures above $17{ }^{\circ} \mathrm{C}$ were chosen, being more appropriate for the coffee plantations. In

\footnotetext{
2 The temperature below which the development ceases or cannot be measured. In this case the development threshold is the base temperature.

3 The thermal constant of each phase establishes the necessary accumulated number of degree-days to complete the phase.
} 
this case, the annual generation number $\left(G_{\bar{\theta}}\right)$ for the region with average annual temperature $\bar{\theta}$ was got through the following equation:

$$
G_{\bar{\theta}}=\sum_{j=1}^{72} G_{\bar{\theta}_{j}}
$$

with $G_{\bar{\theta}_{j}}$ the generation number in $j$-th "pentada" and $\bar{\theta}_{j}$ the average temperature of the $j$-th "pentada" in degree Celsius. It was verified that in these regions it is possible to find about 8-12 generations of $L$. coffeella per year (Table 6).

For the cities Pindorama and Campinas the annual generations' number in the years of 1972-1979 were also calculated based on the records of temperature per "pentada". In Campinas it was possible to find about 8-10 generations of $L$. coffeella per year(Table 7), whereas in Pindorama, about 10-12 generations (Table 8).

The results were compared with the data on population fluctuations of this insect obtained in field conditions for the cities of Campinas and Pindorama in 1973 and 1976 (Tables 7 and 8). The proposed method is shown to be effective for field conditions.

\section{Computer simulation of the dynamics of Leucoptera coffeella populations at different constant temperatures}

In the first part of this work we simulated the population dynamics of the coffee leaf miner submitted to different constant temperatures and compared the results with the experimental data. Considering that the reproductive mode of $L$. coffeella is sexual, we use the Penna Model in the version indicated previously in this work.

It was considered an initial population of $N_{0}$ diploid individuals (50\% males and 50\% females) with their genotypes represented by eight bit-strings that are read in parallel. In such a case, the maximum age allowed for an individual population is 127 days. All positions in the genotype were considered recessive, identifying one Penna bit with one day.

For each temperature $\left(20,27\right.$ and $\left.30^{\circ} \mathrm{C}\right)$ the parameters such as minimum reproduction age $(R)$, that is, developmental time, and fecundity $(B)$ assumed values from the experimental data of Table 1 . In addition, the probability of the oviposition $(\alpha)$, oviposition time $(\beta)$ and pre-oviposition time $(\gamma)$ were considered in the model, as presented in Table 1 . After the mating each female will lay the $B$ eggs with probability $\alpha$. In this case the female initiates the oviposition $\gamma$ days after the mating. In the each day of oviposition time $(\beta)$ the female produce $b$ eggs, defined as $B / \beta$. During its life the female selects only one time a male for mating [10]. In relation to the competition between individuals, those in egg phase did not suffer action of the Verhulst factor.

The other parameters of the model, which are independent of temperature were given the following values:

- carrying capacity: $N_{\max }=100,000$,

- number of mutations: $M=4$,

- limit of deleterious mutations: $T=4$.

With these parameters the population dynamics follows the simple rules for the Penna Model. Simulations were made up to 100,000 temporal steps (“days"), considering an initial population of $N_{0}=10,000$ individuals.

\subsection{Results and discussion}

Figs. 1 and 2 present the survival curves for the females obtained starting from different sets of parameters $R, b$, $\alpha, \beta$ and $\gamma$. It is observed that the survival curves present breakings due to non-competition of individuals in the egg phase.

The curves of the survival of females and males did not present significant differences. In fact controversies exist in relation to this. Parra [2] verified that the females live more than males, in contrast to the results got by Reyes [11], according to which the females live less than males.

In Fig. 1 it was considered that $\alpha=1.0$ for the three temperatures and in Fig. 2 it was considered that values differentiated for $\alpha$ are as presented in Table 1. In the Fig. 1 it is observed that the simulated life expectancy are in the confidence intervals for all tested temperatures (Table 2). The same occurs in Fig. 2 for the temperatures 27 and $30{ }^{\circ} \mathrm{C}$, except at $20^{\circ} \mathrm{C}$ where the population exterminates in $t=2200$ due to the low probability of oviposition $(\alpha=0.33)$. 


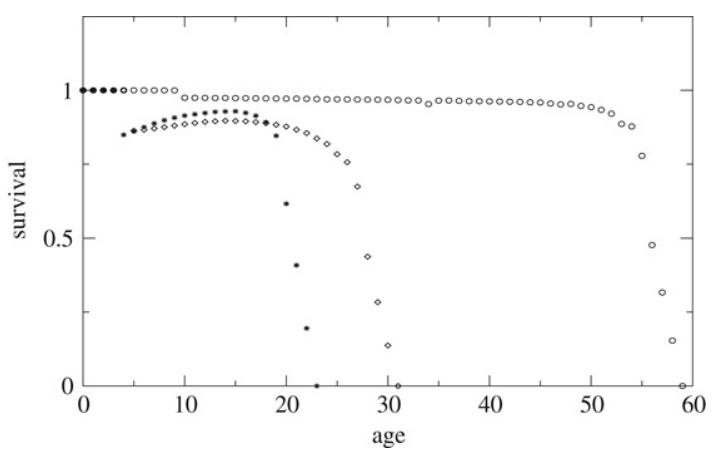

Fig. 1. Survival rates according to age for L. coffeella at 20 (circles), 27 (diamond) and $30{ }^{\circ} \mathrm{C}$ (star) with $\alpha=1.0$. Simulations up to 100,000 temporal steps.

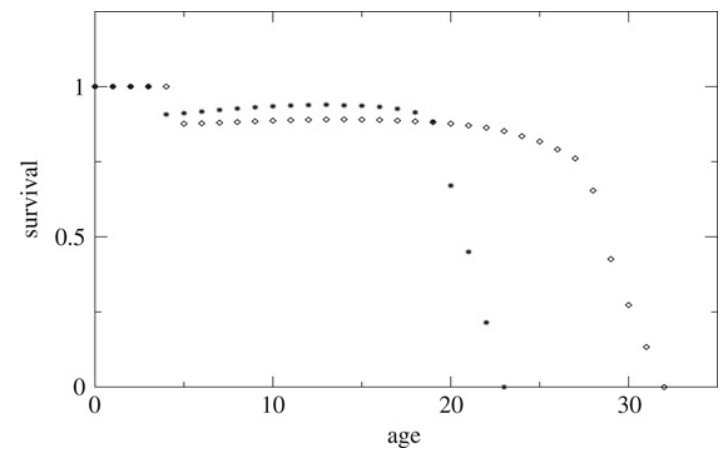

Fig. 2. Survival rates according to age for L. coffeella at 27 (diamond) and $30{ }^{\circ} \mathrm{C}$ (star), with $\alpha=0.93$ and 0.66 , respectively. Simulations up to 100,000 temporal steps.

Table 3

Average values for the population, growth rate and intrinsic growth rate (average \pm half length of the $95 \%$ confidence interval) of $L$. coffeella at the temperatures of 20,27 , and $30^{\circ} \mathrm{C}(\alpha=1.0)$

\begin{tabular}{lcrr}
\hline Temperature & $20{ }^{\circ} \mathrm{C}$ & $27{ }^{\circ} \mathrm{C}$ & $30{ }^{\circ} \mathrm{C}$ \\
\hline Average values for the population & $2406.6 \pm 2.16$ & $11626.5 \pm 29.86$ & $10485.9 \pm 43.14$ \\
Average growth rate & $1.025 \pm 0.0001$ & $1.135 \pm 0.0008$ & $1.131 \pm 0.0018$ \\
Average intrinsic growth rate & $0.024 \pm 0.0001$ & $0.124 \pm 0.0007$ & $0.112 \pm 0.0015$ \\
\hline
\end{tabular}

The growth rate of population $(\lambda(t))$ was calculated in accordance with the discrete logistic equation [12]:

$$
N(t+1)=\lambda(t) N(t)\left[1-N(t) / N_{\max }\right] .
$$

Tables 3 and 4 present the average values for the population, growth rate and intrinsic growth rate $r_{m}(t)$, defined as $r_{m}(t)=\ln (\lambda(t))$ [13]. The average values were calculated not considering the 60,000 initial temporal steps. Considering different values for $\alpha$ (Table 1), significant differences were observed between the temperatures of 27 and $30^{\circ} \mathrm{C}$ (Table 4). These results are according to the experimental results presented in Table 1. The temperature of $27^{\circ} \mathrm{C}$ is the most favourable for the population growth of L. coffeella.

Fig. 3 presents the Fourier spectrum of the correlation function for population size at $27^{\circ} \mathrm{C}$ with $\alpha=0.93$. In the population dynamics, a non-periodic regime characterized by random-like fluctuations superimposed to periodic components appears. From the Fourier spectrum of the population size (Fig. 4) it is verified that the period of higher amplitude coincides with the time necessary to reach the maturity plus the duration of the egg phase (excluded phase of the competition between individuals). This result is valid also for $\alpha=1.0$ and other temperatures $\left(20\right.$ and $\left.30^{\circ} \mathrm{C}\right)$. 


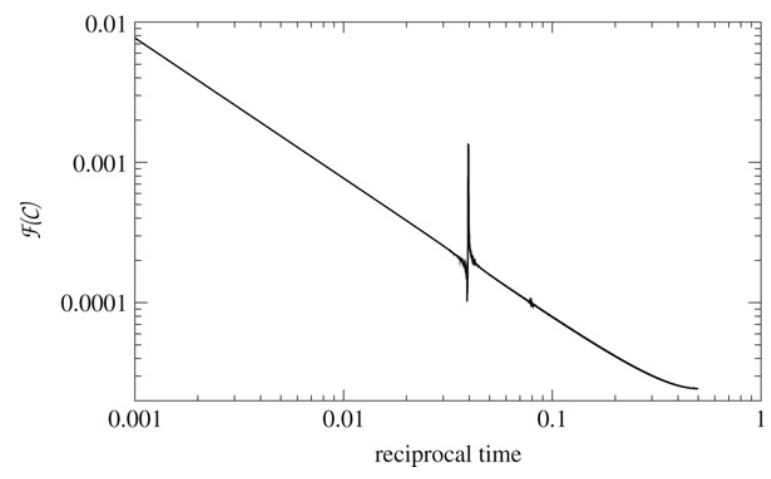

Fig. 3. Fourier spectrum of the correlation function of the population size (log-log scale).

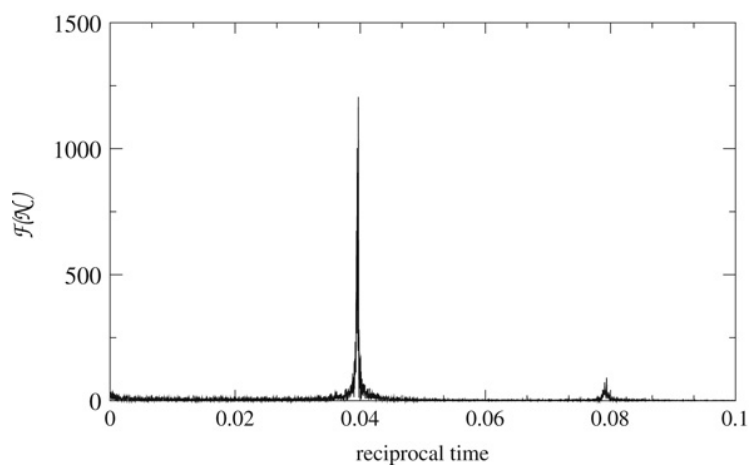

Fig. 4. Fourier spectrum of the population size.

Table 4

Average values for the population, growth rate and intrinsic growth rate (average \pm half length of the $95 \%$ confidence interval) of $L$. coffeella at the temperatures of 27 , and $30^{\circ} \mathrm{C}$ ( $\alpha$ assumed different values in accordance with Table 1)

\begin{tabular}{lrr}
\hline Temperature & $27^{\circ} \mathrm{C}$ & $30{ }^{\circ} \mathrm{C}$ \\
\hline Average values for the population & $11317.5 \pm 20.82$ & $7162.4 \pm 19.74$ \\
Average growth rate & $1.129 \pm 0.0006$ & $1.082 \pm 0.0010$ \\
Average intrinsic growth rate & $0.120 \pm 0.0005$ & $0.075 \pm 0.0009$ \\
\hline
\end{tabular}

\section{Computer simulation of the dynamics of $L$. coffeella populations at different variable temperatures}

The purpose of this simulation is to get the number of annual generations of $L$. coffeella subjected to temperature variations and to compare it with the field data. In each temporal step, females with age higher than or equal to $R(\theta)$, being $\theta$ the temperature, will be fertilized only once. The pre-oviposition time $(\gamma(\theta))$ and fecundity $(B(\theta))$ assume the corresponding values of the temperature where the fertilization occurred. The fertilized females will lay $B(\theta)$ eggs with probability $\alpha(\theta)$. The daily fecundity $b(\theta)$ is updated at each temporal step as a function of the temperature. This means that the fertilized female lays eggs until all the $B(\theta)$ eggs have been laid. The duration of the phase of egg $(\epsilon(\theta))$, that is, the age at which the individual hatches out of the egg, is also updated at each temporal step. Having reached this age in one temporal step, the individual hatched out of the egg and from this moment it competes with the other individuals of the population for space and food.

Once the temperature varies with the time, the model parameters depending on the temperature, $R(\theta), B(\theta), b(\theta)$, $\epsilon(\theta), \alpha(\theta)$ and $\gamma(\theta)$ were updated according to following equations:

$$
\begin{aligned}
& R(\theta)=32458.90 \exp (-0.35 \theta)+17.28, \\
& B(\theta)=86.28 \exp \left(-0.09(\theta-25)^{2}\right),
\end{aligned}
$$


Table 5

Annual generations' number of L. coffeella on the basis of annual average temperatures

\begin{tabular}{lll}
\hline Annual average temperature $\left({ }^{\circ} \mathrm{C}\right)$ & \multicolumn{2}{l}{ Annual generations number } \\
\cline { 2 - 2 } & Simulation & Method \\
\hline $17-18$ & $4.0-.5 .0$ & $4.4-5.8$ \\
$18-19$ & $5.0-6.0$ & $5.8-7.2$ \\
$19-20$ & $6.0-8.0$ & $7.2-8.4$ \\
$20-21$ & $8.0-9.0$ & $8.4-9.7$ \\
$21-22$ & $9.0-10.0$ & $9.7-10.9$ \\
$22-23$ & $10.0-12.0$ & $10.9-12.2$ \\
$>23$ & $>12.0$ & $>12.2$ \\
& &
\end{tabular}

$$
\begin{aligned}
& b(\theta)=0.39 \theta-6.95, \\
& \epsilon(\theta)=1471.11 \exp (-0.27 \theta)+3.67, \\
& \alpha(\theta)=0.983 \exp \left(-0.031(\theta-26)^{2}\right), \\
& \gamma(\theta)=51.98 \exp (-0.14 \theta),
\end{aligned}
$$

with $\theta$ the temperature in degree Celsius.

The model parameters independent from temperature had the same values of the previous simulation. Simulations were made up to 360 temporal steps ("days"), considering an initial population of $N_{0}=10,000$ individuals $(50 \%$ males and 50\% females). Each individual of the initial population corresponds to the first generation. Each generated son has its generation developed as a unit in relation to its mother. The population dynamics follows basically the simple rules of the previous simulation.

\subsection{Annual generation number on the basis of annual average temperatures}

In this case some simulations were carried out by considering each temporal step a constant and the temperature equal to the annual average value in the interval of 17 to $23^{\circ} \mathrm{C}$, as in reference [2].

\subsubsection{Results and discussion}

Considering different annual average temperatures, the obtained values for annual generations' number in some intervals of temperature are presented in Table 5.

For the temperatures of 17,18 and $19{ }^{\circ} \mathrm{C}, \alpha=1.0$ was considered. With different values for $\alpha$, the population becomes extinct in these cases. For other temperatures the generation number is the same, either $\alpha=1.0$ or dependent on the temperature as defined in Eq. (10). It was verified that the results obtained through simulation are close to the ones obtained through the methods presented in [2]. Moreover, in more favourable regions of the coffee production (average temperatures between 18 and $22{ }^{\circ} \mathrm{C}$ ), it is possible to occur about 5-11 annual generations. This is in agreement with the observations of Gonzales et al. [14], according to which this species can present up to 15 annual generations.

\subsection{Annual generations' number of the main coffee growing regions of the State of São Paulo}

\subsubsection{Results and discussion}

Simulations were carried out for different cities of São Paulo/Brazil, considering historic average of the temperature per "pentada" (to each 5 days), obtained from reference [2]. In this case the temperature is brought up-to-date to each 5 temporal step. The obtained values for annual generations' number are presented in Table 6. On comparing the results of methods and simulations, small differences are noticed in some cases.

Simulations were carried out for the cities of Campinas and Pindorama in the years of 1972-1979, from registers of temperature per "pentada". The results of the simulations show small differences in relation to one obtained by the method (Tables 7 and 8). Moreover, comparing the results of the simulations to the ones of field for the cities of Campinas and Pindorama in the years of 1973 and 1976, it is verified small difference as occurs with the method presented in [2]. 
Table 6

Annual generations' number of L. coffeella for different cities of the state of São Paulo, Brazil

\begin{tabular}{llcr}
\hline City & Annual generations' number & \\
\cline { 2 - 4 } & Annual average temperature $\left({ }^{\circ} \mathrm{C}\right)$ & Simulation & Method \\
\hline Ataliba Leonel & 19.9 & 8 & 8 \\
Cássia dos Coqueiros & 19.9 & 7 & 9 \\
Campinas & 20.7 & 9 & 8 \\
Jaú & 21.6 & 10 & 11 \\
Mococa & 21.9 & 10 & 11 \\
Ribeirão Preto & 21.9 & 10 & 11 \\
Presidente Prudente & 22.9 & 11 & 12 \\
Pindorama & 22.2 & 11 \\
\hline
\end{tabular}

Table 7

Annual generations' number of L. coffeella in the years of 1972-1979, Campinas, SP

\begin{tabular}{llrrr}
\hline Year & Annual generations' number & & Method \\
\cline { 2 - 5 } & Annual average temperature $\left({ }^{\circ} \mathrm{C}\right)$ & Simulation & 9 & Experimental \\
\hline 1972 & 20.7 & 10 & 10 & - \\
1973 & 21.0 & 10 & 9 & - \\
1974 & 20.6 & 10 & 9 & - \\
1975 & 20.2 & 10 & 8 & - \\
1976 & 19.9 & 8 & 10 & - \\
1977 & 21.4 & 10 & 9 & - \\
1978 & 20.9 & 10 & 9 & - \\
1979 & 20.5 & 9 & & - \\
\hline
\end{tabular}

Table 8

Annual generations' number of L. coffeella in the years of 1972-1979, Pindorama, SP

\begin{tabular}{lllll}
\hline Year & Annual generations' number & & \\
\cline { 2 - 5 } & Annual average temperature $\left({ }^{\circ} \mathrm{C}\right)$ & Simulation & Method & 11 \\
\hline 1972 & 21.9 & 11 & 12 & Experimental \\
1973 & 22.7 & 12 & 11 & - \\
1974 & 22.3 & 12 & 12 & - \\
1975 & 22.4 & 11 & 10 & - \\
1976 & 21.3 & 10 & 12 & - \\
1977 & 22.7 & 12 & 11 & - \\
1978 & 22.1 & 12 & 11 & - \\
1979 & 21.9 & 11 & 2 \\
\hline
\end{tabular}

From the obtained results it is verified that the annual generation number can differ in situations of same annual average temperature, indicating considerable sensitivity in relation to the way as the temperature varies in the considered period.

\section{Conclusions}

Considering the obtained results it is verified that the computer simulation is able to efficiently reproduce the relative aspects of the biology of the coffee leaf miner under the laboratory conditions at different temperatures. Moreover, it has shown to be efficient in forecasting the annual generation number of the pest in field conditions. Although, the temperature is not the only regulating element of the dynamics of the pests, the simulation can be used to foresee the coffee leaf miner population peaks and to supply support for pest integrated management programs in different coffee regions.

Eventhough the method proposed in [2] is sufficiently efficient for forecasting the probable number of generations, it does not make possible to deal with the dynamic aspects of interaction in a population. In contrast, computer simulations, as a forecast model, allow to deal with the different aspects. 


\section{References}

[1] L. Zambolim, Manejo Integrado, Doenças, Pragas e Plantas Daninhas, Departamento de Fitopalogia, UFV, Viçosa, 2000.

[2] J.R.P. Parra, Rvta. Bras. Ent. 29 (1) (1985) 45;

J.R.P. Parra, M.de L. Haddad, S.S. Neto, Revta. Bras. Ent. 39 (1) (1995) 125;

W. Goncalves, J.R.P. Parra, W.L. Salgado, Dois predadores de lagartas do bicho-mineiro (Guèrin:Meneville, 1842), Congresso Brasileiro de Pesquisas Cafeeiras 3 (1975) 196.

[3] D.E. Nava, M.de L. Haddad, J.R.P. Parra, Pesq. Agrop. Bras. 40 (10) (2005) 961.

[4] J.C. de Souza, P.R. Reis, R.L.de O. Rigitano, Bicho Mineiro do cafeeiro: biologia, danos e manejo integrado, Epamig, Boletim Técnico 54, Belo Horizonte, 1998.

[5] E.de S. Tuelher, E.E. de Oliveira, R.N.C. Guedes, L.C. Magalhães, Acta Scientiarium 25 (1) (2003) 119.

[6] L.T.P. Giarola, S.G.F. Martins, M.C.P. Toledo Costa, Physica A 368 (2006) 147.

[7] T.J.P. Penna, J. Stat. Phys. 78 (1995) 1629.

[8] A.T. Bernardes, Ann. Physik 5 (1996) 539.

[9] D. Stauffer, P.M.C. de Oliveira, S. Moss de Oliveira, R.M. Zorzenon dos Santos, Physica A 231 (1996) 504.

[10] M. Speer, Arquivos do Instituto Biológico 19 (1949) 39.

[11] J.A.O. Reyes, Acta Agronomica 23 (1973) 19.

[12] A.T. Bernardes, J.-G. Moreira, A. Castro-e-Silva, Eur. Phys. J. B 1 (1998) 393.

[13] S. Siveira Neto, D.O. Nakano, N.A. Barbin, in: São Ceres, Paulo (Eds.), Manual de ecologia dos insetos, 1976.

[14] C.V. Gonzales, E. Konnorova, J. Jasic, Ciência. Série 4: Ciências Biológicas, La Habana 26 (1) (1972). 